\title{
Penerapan dan Analisis Digital Marketing pada Produk Fashion
}

\author{
http://dx.doi.org/10.28932/jutisi.v7i2.3705 \\ Riwayat Artikel \\ Received: 18 Juni 2021 | Final Revision: 12 Juli 2021 | Accepted: 16 Juli 2021 \\ Sylvia Princesa ${ }^{\bowtie \# 1}$, Yenni Merlin Djajalaksana² \\ \# Program studi Sistem Informasi, Fakultas Teknologi Informasi, Universitas Kristen Maranatha \\ Jln. Prof. Drg. Surya Sumantri No. 65, Sukawarna, Bandung. \\ 11773021@maranatha.ac.id \\ ${ }^{2}$ yenni.md@maranatha.ac.id
}

\begin{abstract}
In the current digital era, digital marketing is a marketing strategy using digital media to reach customers quickly and widely. About She is a fashion brand located in Bandung that tries to do digital marketing to promote fashion products through social media and websites. We can see website performance with Google Analytics, as well as social media analysis through Instagram Insight and Facebook Insight.
\end{abstract}

Keywords — Digital Marketing; Facebook; Instagram; Website.

\section{Pendahuluan}

Saat ini dunia bisnis semakin berkembang dengan pesat. Hal ini membuat para pemilik usaha harus mencari solusi dan memikirkan strategi-strategi yang dapat menjamin keberlangsungan bisnis mereka. Setiap pemilik usaha harus bisa membaca keadaan pasar terkini. Saat ini banyak perusahaan tidak lagi menggunakan cara marketing yang manual, tetapi sudah beralih dengan menggunakan sebuah digital yaitu dengan menerapkan digital marketing.

Menurut (Rachmadi, 2020) Digital marketing merupakan strategi pemasaran yang dapat menjangkau konsumen secara luas dan tepat, mempermudah konsumen untuk memperoleh informasi mengenai produk yang ditawarkan serta mempermudah konsumen dalam melakukan transaksi tanpa harus datang langsung ke toko untuk mengefisien waktu [1]. Kelebihan dari Digital Marketing yaitu dapat mempromosikan dan menjual secara luas, hemat dalam biaya, tenaga, konsumen dapat mengetahui spesifikasi produk melalui internet dan dapat diakses kapanpun dan dimanapun [2]. Dengan menerapkan digital marketing, dapat membantu perusahaan dan para pengusaha dalam meningkatkan strategi penjualannya.

Terdapat 3 strategi dalam menerapkan digital marketing yaitu website, social media marketing, Search Engine Optimization (SEO). Website merupakan sebuah kumpulan halaman yang ada di internet, halaman tersebut berupa konten yang isinya yaitu teks, suara ataupun gambar [3]. Social Media Marketing yaitu bentuk pemasaran melalui internet yang melibatkan pembuatan dan membagikan konten di jaringan sosial untuk mencapai tujuan branding dan promosi [4]. Search Engine Optimization (SEO) adalah proses untuk membuat sebuah website muncul di ranking tertinggi dari hasil pencarian pada saat seorang pengguna internet memasukkan kata kunci yang relevan di dalam search engine [5].

About She merupakan suatu brand fashion yang mulai melihat peluang untuk memasarkan produknya melalui digital marketing. Tujuannya yaitu untuk mengenali produk yang ditawarkan oleh About She kepada masyarakat secara luas. Langkah pemasaran yang dilakukan saat ini masih menggunakan cara yang manual yaitu secara offline seperti konsumen datang langsung ke toko untuk melakukan transaksi dan memperoleh informasi produk yang ditawarkan.

Penerapan digital marketing yang dilakukan yaitu membuat sebuah website yang berisi informasi produk dan dapat melakukan transaksi pembelian secara online, melakukan promosi melalui social media Instagram dan Facebook. Pada social media lebih banyak membuat konten yang sesuai dengan target konsumen. Dalam beberapa cara penerapan digital marketing, tentu dibutuhkan seperti penggunaan hashtag penggunaan fitur ads di social media, penerapan search engine optimization (SEO) pada website dan masih banyak lainnya. Setelah itu hasil dari penerapan digital marketing tersebut dianalisis dan dievaluasi melalui Instagram dan Facebook insight dan untuk website menggunakan google analytics sehingga dapat melakukan perubahan dan pembuatan campaign baru yang lebih sesuai dengan target konsumen. 


\section{METODE PENELITIAN}

\section{A. Rencana}

Rencana yang dilakukan dalam implementasi digital marketing yaitu

1. Pembuatan akun Instagram dan Facebook page beserta konten dimulai pada 29 September 2020 hingga 28 Februari 2021.

2. Pembuatan website dimulai pada 10 Oktober 2020 hingga 28 Februari 2021.

3. Penerapan Instagram ads dimulai pada 19 November 2020 hingga 24 November 2020.

4. Melakukan Giveaway di Instagram pada 5 Februari 2021 hingga 8 Februari 2021.

5. Analisis Instagram dan Facebook page dimulai pada 29 September 2020 hingga 28 Februari 2021.

6. Analisis website menggunakan Google Analytic dimulai pada 17 November 2020 hingga 28 Februari 2021.

B. Tampilan Social Media

1) Instagram : Gambar 1 merupakan Instagram dari About She yang telah memiliki 193 followers, 52 post dan 281 following.

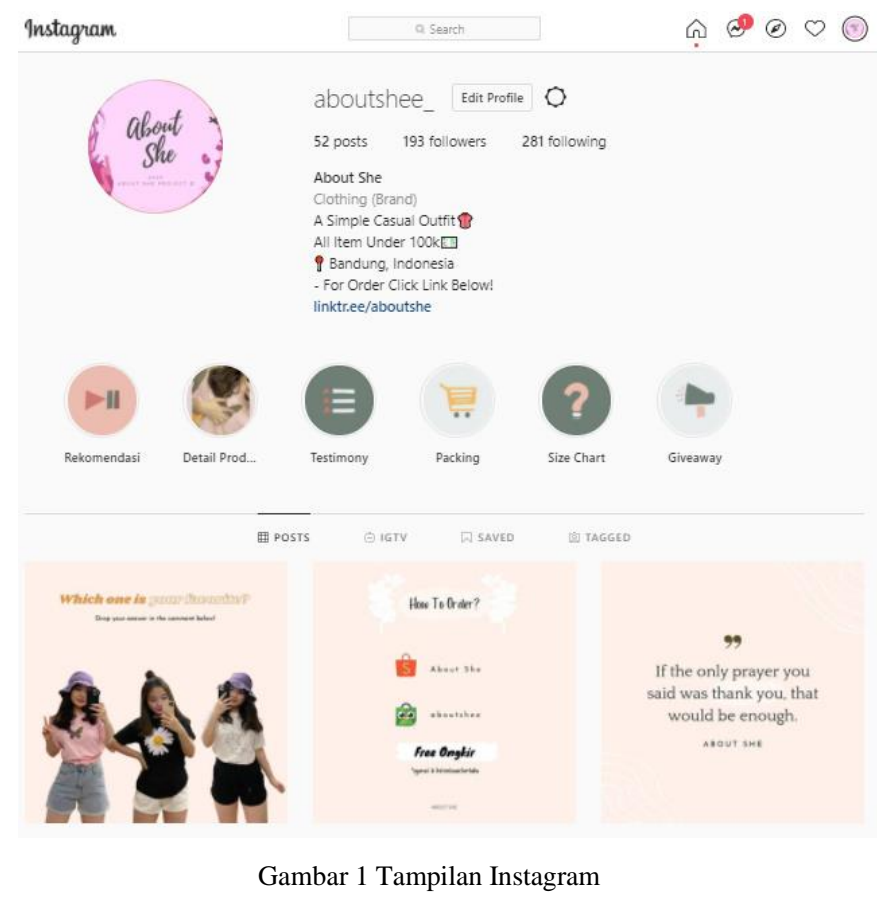

2) Facebook Page : Gambar 2 ,merupakan Facebook Page dari About She yang telah memiliki 15 like page. Facebook Page ini terintegrasi oleh Instagram About She. 


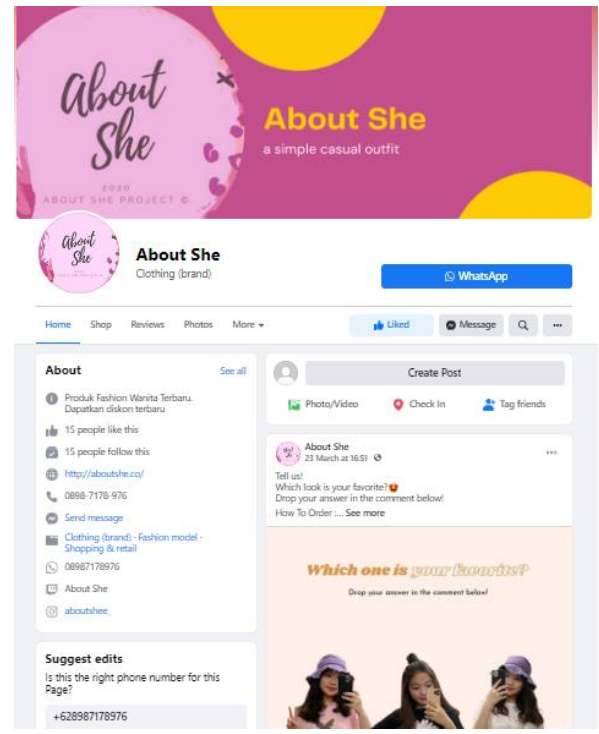

Gambar 2 Tampilan Facebook Page

\section{Tampilan Website}

Gambar 3 merupakan tampilan halaman Home. Terdapat slider yang berisi informasi mengenai produk, promosi yang ditawarkan, terdapat tombol Whatsapp jika di klik akan langsung me-redirect ke aplikasi Whatsapp yang memudahkan pengguna dalam menghubungi About She.

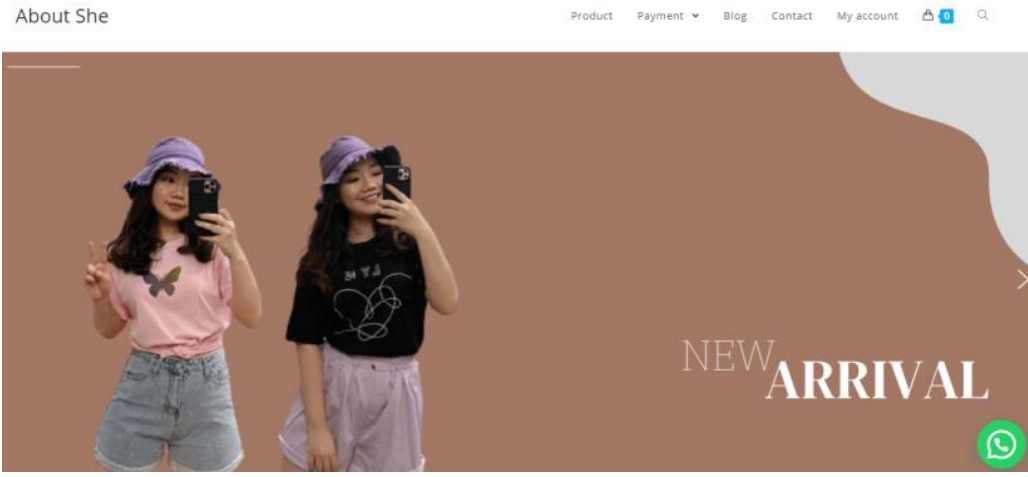

Gambar 3 Halaman Home Website

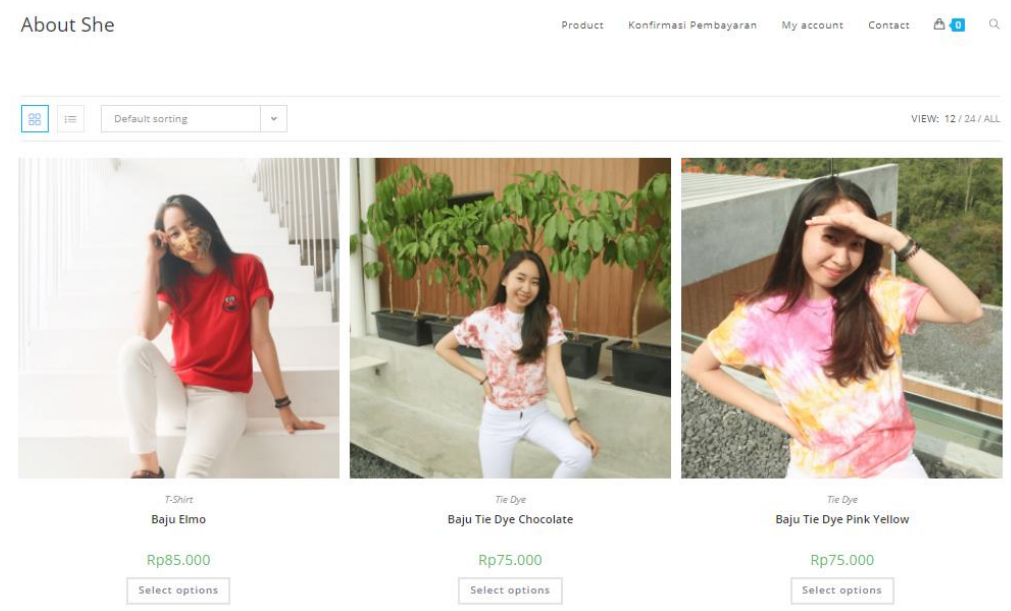

Gambar 4 Halaman Product Website 
Gambar 4 merupakan tampilan halaman Product. Terdapat item-item product beserta informasi mengenai product yang ditawarkan oleh About She.

About She
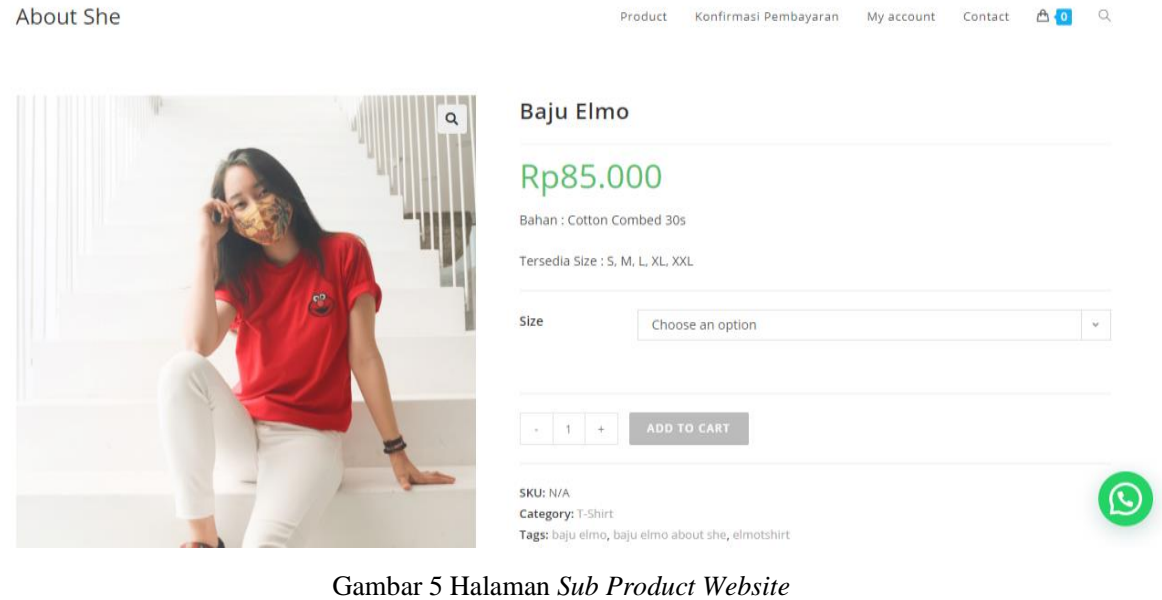

Gambar 5 merupakan tampilan halaman sub product. Saat meng-klik product di halaman product lalu akan langsung meredirect ke halaman sub product ini. Pada halaman sub product, terdapat informasi detail mengenai product yang dipilih seperti harga product, size yang tersedia, dan masih banyak lainnya.

\section{HASIL DAN PEMBAHASAN}

\section{A. Hasil dan Analisis Instagram}

Untuk menganalisa Instagram, About She menggunakan Instagram Insight agar dapat menganalisis dengan hasil yang akurat. Instagram Insight merupakan salah satu tools yang terdapat di Instagram untuk mengukur keseluruhan kinerja konten dengan audiens [6]. Tools ini digunakan untuk mengukur dan menganalisis data insight pada Instagram seperti perkembangan reach, audience, content interactions.

\section{FOLLOWERS}

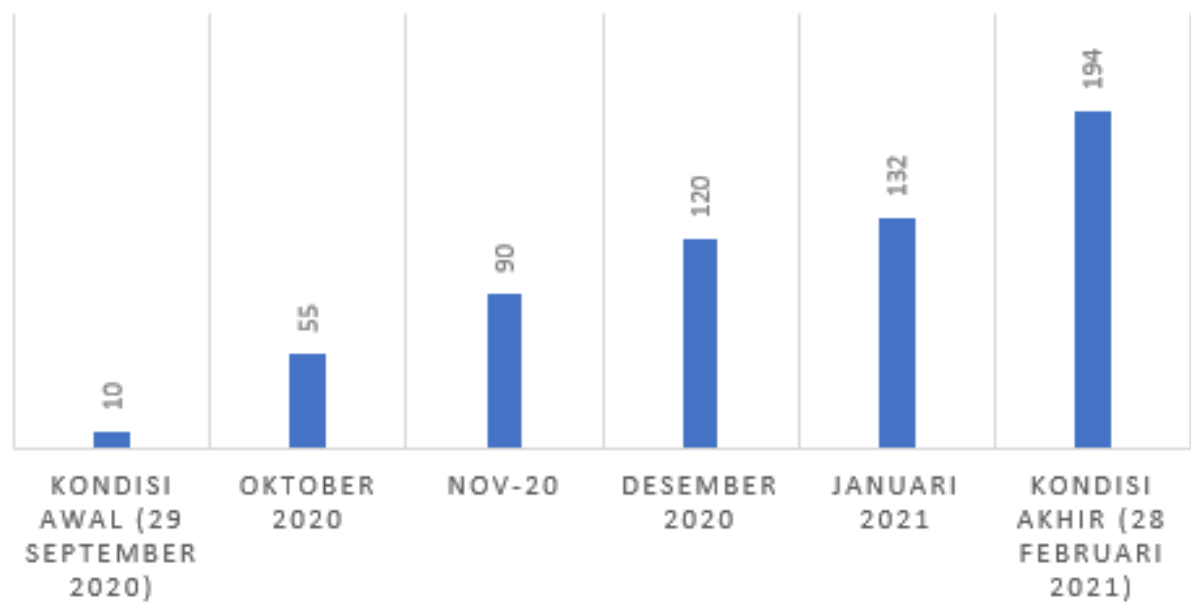

Gambar 6 Hasil Perkembangan Followers Instagram

Pada Gambar 6 menggambarkan perkembangan followers pada Instagram About She dimulai pada 29 September 2020 hingga 28 Februari 2021. Followers About She semakin bertambah dan kini memiliki 194 Followers. Pada bulan Februari mengalami kenaikan followers dikarenakan melakukan Giveaway sehingga terjadi banyak interaksi untuk follow Instagram About She. 


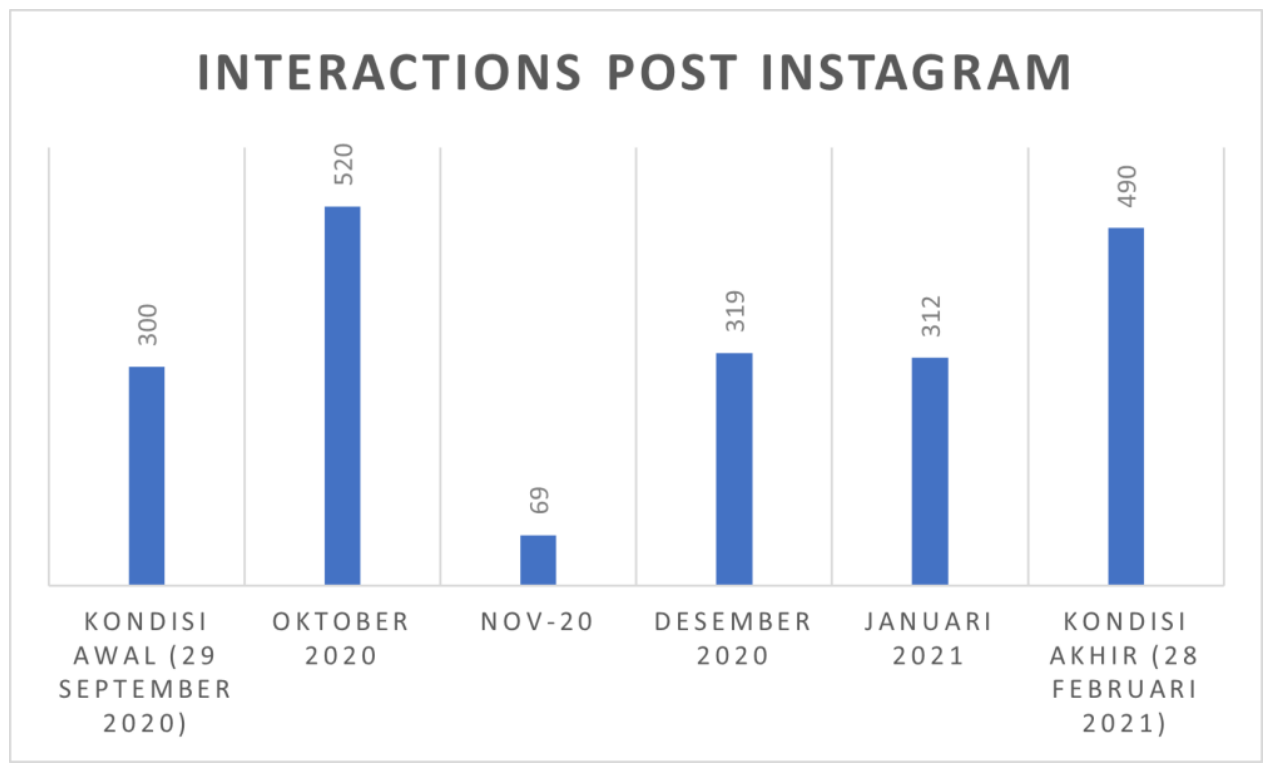

Gambar 7 Hasil Interactions Instagram

Pada Gambar 7, terdapat grafik yang menunjukkan perkembangan engagement pada Instagram dari bulan September 2020 hingga bulan Februari 2021. Interactions merupakan jumlah pengguna yang melihat content, memberikan reaksi like, comment, share, save pada post di Instagram. Pada bulan November 2020, mengalami penurunan dibandingkan dengan bulan lainnya, dikarenakan pada bulan tersebut, kurangnya konten yang menarik perhatian target konsumen. Lalu pada bulan Oktober 2020 mengalami kenaikan dikarenakan sedang menerapkan Instagram Ads. Pada bulan Februari 2021, mengalami kenaikan dikarenakan pada bulan tersebut sedang dilakukan Giveaway sehingga banyak interaksi dalam melakukan like, comment, share pada Instagram About She.

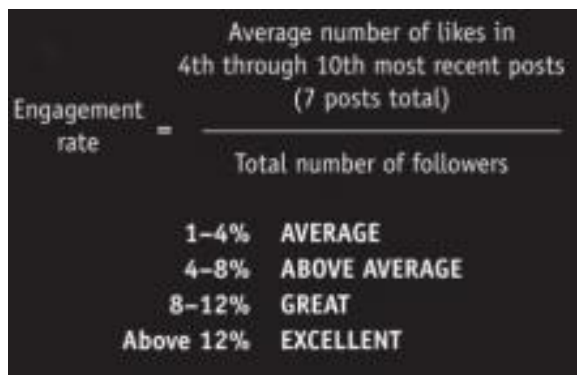

Gambar 8 Perhitungan Engagement Rate

Efektivitas penggunaan Instagram dapat dilihat dari engagement rate. Gambar 8 merupakan rumus untuk mengukur engagement pada Instagram [7]. Berdasarkan data dari 29 September 2020 hingga 28 Februari 2021, hasil perhitungan engagement Instagram berada di angka $10.21 \%$ yang termasuk dalam tingkat baik. Ini menunjukkan bahwa Instagram About She dapat dikatakan efektif sebagai media promosi.

\section{B. Hasil dan Analisis Facebook}

Untuk menganalisis Facebook, About She menggunakan Facebook Page Insight agar dapat menganalisis dengan hasil yang akurat. Facebook Page Insight merupakan tools yang terdapat di Facebook untuk membantu dalam mempelajari lebih lanjut mengenai target audiens dan konten apa yang paling sesuai dengan target audiens [8]. Tools ini digunakan untuk mengukur dan menganalisis data insight pada Instagram seperti perkembangan reach, audience, content interactions. 


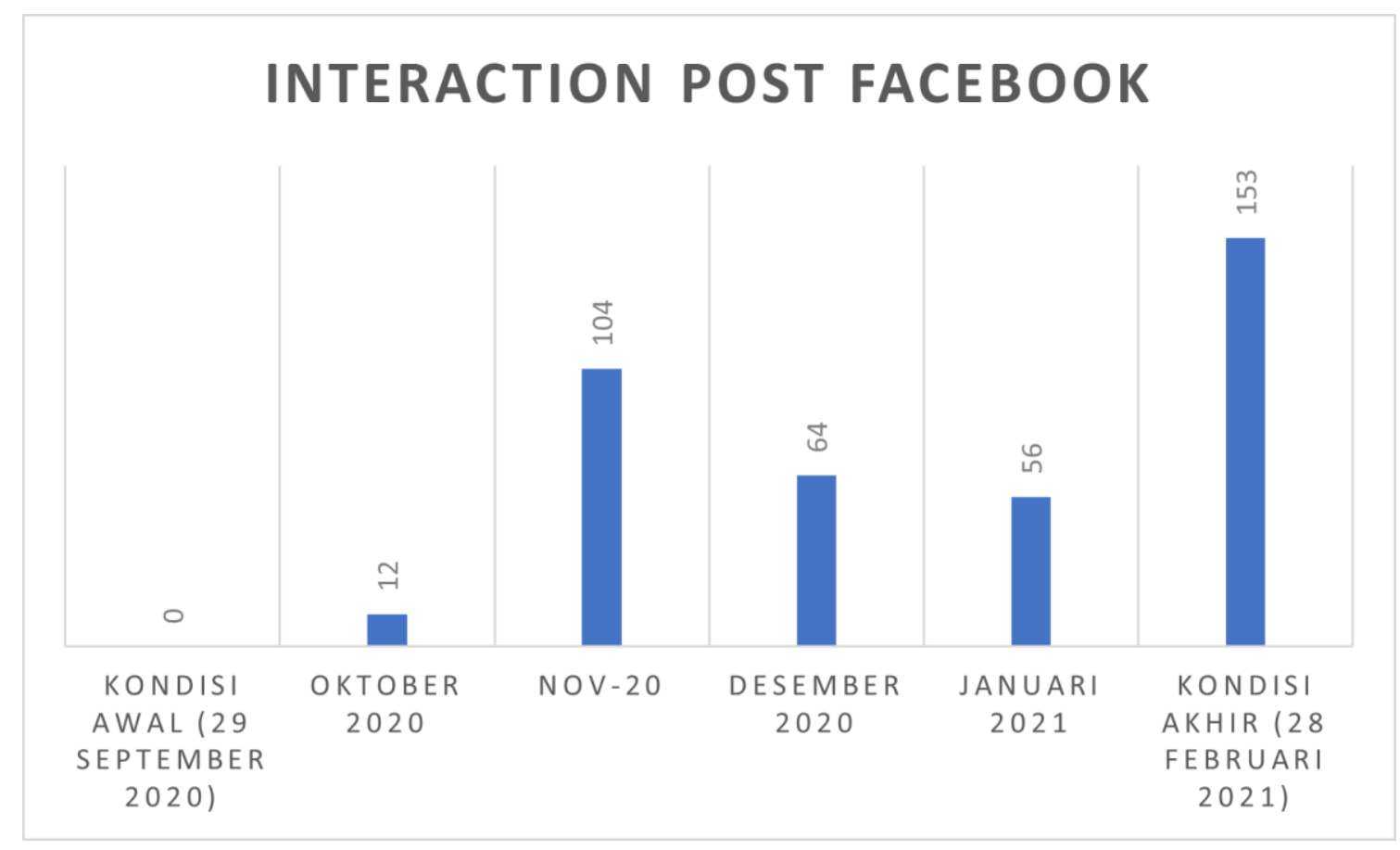

Gambar 9 Hasil Interactions pada Facebook

Pada Gambar 9, menunjukkan perkembangan Like Post pada Facebook Page About She dari bulan September hingga Februari 2021. Pada bulan November mengalami kenaikan dibandingkan pada bulan November yaitu terdapat 104 likes. Lalu pada bulan Desember hingga Januari mengalami penurunan. Pada bulan Februari mengalami kenaikan dikarenakan pada bulan tersebut, terdapat banyak konten yang membuat menarik audience.

TABEL 1

HASIL ENGAGEMENT RATE PADA FACEBOOK

\begin{tabular}{cc}
\hline Deskripsi & Total (September - Februari 2021) \\
\hline $\begin{array}{c}\text { Total Like, Comment, } \\
\text { Share, Post }\end{array}$ & 392 \\
\hline Total Follow Page & 15 \\
\hline Engagement Rate & $\mathbf{2 . 6 1 \%}$ \\
\hline
\end{tabular}

Berdasarkan Gambar 8, dapat disimpulkan bahwa engagement rate pada Facebook Page About She yang terdapat pada Tabel 1 yaitu 2.61\%. Pada Tabel 2 merupakan klasifikasi mengenai engagement rate pada Facebook. Berdasarkan Tabel 2 klasifikasi engagement rate pada Facebook, disimpulkan bahwa engagement rate pada Facebook Page About She dari bulan September hingga Februari 2021 menunjukkan klasifikasi yang sangat baik yaitu diatas 1\%.

TABEL 2

KLASIFIKASI ENGAGEMENT RATE PADA FACEBOOK

\begin{tabular}{cc}
\hline Engagement Rate & Klasifikasi \\
\hline$<\mathbf{0 . 5 \%}$ & Rendah \\
\hline $\mathbf{0 . 5 \% - 0 . 9 9 \%}$ & Rata-Rata/Baik \\
\hline$>\mathbf{1 \%}$ & Sangat Baik \\
\hline
\end{tabular}




\section{Analisis Website menggunakan Google Analytic}

Untuk menganalisa website, About She menggunakan Google Analytic agar dapat menganalisis dengan hasil yang akurat. Google Analytic merupakan tools untuk menganalisis kinerja dengan audiens pada sebuah website [9]. Google Analytic dapat digunakan untuk mengetahui perkembangan visitor website, melacak, melihat detail audience.

Pada Gambar 10, dapat disimpulkan pada bulan Februari 2021 bahwa terdapat 27 pengguna yang mengunjungi website. 24 pengguna merupakan pengunjung baru. 3 pengguna merupakan pengguna yang sudah pernah mengakses sebelumnya. Pada bulan Februari 2021 ini mengalami kenaikan dibandingkan dengan bulan sebelumnya dikarenakan telah menambahkan item product baru dan menambahkan blog pada website.

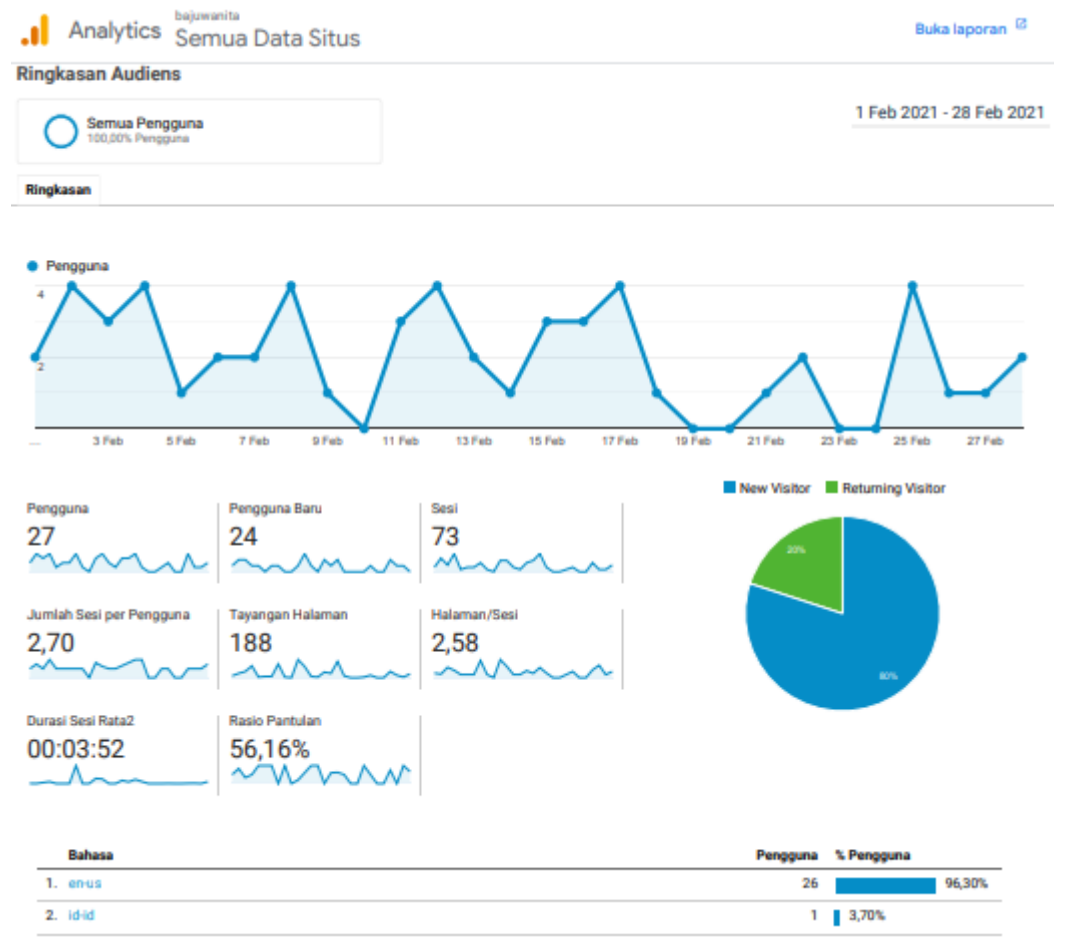

Gambar 10 Ringkasan Audiens pada bulan Februari 2021

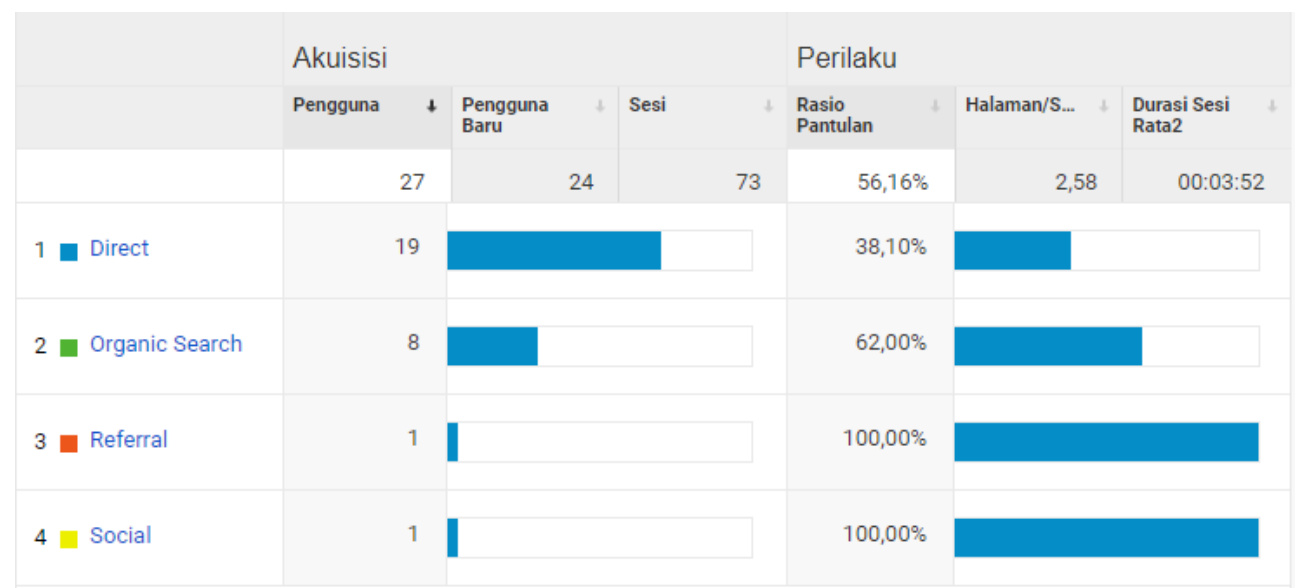

Gambar 11 Ringkasan Akuisisi Website pada Februari 2021 
Pada Gambar 11 merupakan Ringkasan Akuisisi bulan Februari 2021, menunjukkan bahwa pada bulan Februari 2021 terdapat 19 pengguna yang mengakses website About She melalui Direct, 8 pengguna yang mengakses website melalui Organic Search , 1 pengguna yang mengakses website melalui Referral dan terdapat 1 pengguna yang mengakses website melalui Social. Dapat disimpulkan bahwa penelusuran Direct lebih optimal dalam meningkatkan grafik pada website.

\begin{tabular}{|c|c|c|c|c|c|c|c|c|c|c|}
\hline \multirow[b]{2}{*}{ Halaman Landing } & \multicolumn{5}{|l|}{ Akuisisi } & \multicolumn{2}{|l|}{ Perilaku } & \multicolumn{3}{|l|}{ Konversi } \\
\hline & Tayangan & Klik & CTR & $\begin{array}{c}\text { Posisi } \\
\text { Rata-Rata }\end{array}$ & Sesi & $\begin{array}{c}\text { Rasio } \\
\text { Pantulan }\end{array}$ & Halaman/Sesi & $\begin{array}{l}\text { Penuntasan } \\
\text { Sasaran }\end{array}$ & $\begin{array}{c}\text { Nillai } \\
\text { Sasaran }\end{array}$ & $\begin{array}{l}\text { Rasio } \\
\text { Konversi } \\
\text { Sasaran }\end{array}$ \\
\hline & $\begin{array}{r}\mathbf{4 1 0} \\
8 \text { Totat: } \\
100,000 \\
(410)\end{array}$ & $\begin{array}{r}30 \\
\text { 8Total: } \\
100,00 \% \\
(30)\end{array}$ & $\begin{array}{r}7,32 \% \\
\text { Rta. untuk } \\
\text { Tampilan: } \\
7,32 \% \\
(0,00 \%)\end{array}$ & $\begin{array}{r}4,3 \\
\text { Rta. untuk } \\
\text { Tampilan: } \\
4,3 \\
(0,00 \%)\end{array}$ & $\begin{array}{r}7 \\
\text { \% Totat: } \\
2,465 \\
(285)\end{array}$ & $\begin{array}{r}71,43 \% \\
\text { Rta. untuk } \\
\text { Tampilan: } \\
60,00 \% \\
(19,05 \%)\end{array}$ & $\begin{array}{r}2,29 \\
\text { Rta. untuk } \\
\text { Tampilan: } \\
2,46 \\
(-7,07 \%)\end{array}$ & $\begin{array}{r}0 \\
8 \text { Total: } \\
0,000 \% \\
(0)\end{array}$ & $\begin{array}{r}\text { Rp } 0,00 \\
\text { \% Total: } \\
0,00 \% \\
(\text { Rp } 0,00)\end{array}$ & $\begin{array}{r}\mathbf{0 , 0 0 \%} \\
\text { Rta. } \\
\text { untuk } \\
\text { Tampilan } \\
\\
0,00 \% \\
(0,00 \%)\end{array}$ \\
\hline 1. / & $\begin{array}{r}99 \\
(24,15 \%)\end{array}$ & $\begin{array}{r}9 \\
(30,00 \%)\end{array}$ & $9,09 \%$ & 1,5 & $\begin{array}{r}7 \\
(100,008)\end{array}$ & $71,43 \%$ & 2,29 & $\begin{array}{r}0 \\
(0,00 \%)\end{array}$ & $\begin{array}{r}\mathrm{Rp} 0,00 \\
(0,00 \mathrm{~s})\end{array}$ & $0,00 \%$ \\
\hline 2. /contact// & $\begin{array}{r}39 \\
(9,51 \%)\end{array}$ & $\begin{array}{r}2 \\
(6,67 x)\end{array}$ & $5,13 \%$ & 3,6 & $\begin{array}{r}0 \\
(0,00 x)\end{array}$ & $0,00 \%$ & 0,00 & $\begin{array}{r}0 \\
(0,00 \%)\end{array}$ & $\begin{array}{r}\operatorname{Rp} 0,00 \\
(0,00 \%)\end{array}$ & $0,00 \%$ \\
\hline 3. /about/ & $\begin{array}{r}37 \\
(9,02 \%)\end{array}$ & $\begin{array}{r}0 \\
(0,00 \%)\end{array}$ & $0,00 \%$ & 3,8 & $\begin{array}{r}\mathbf{0} \\
(0,00 \%)\end{array}$ & $0,00 \%$ & 0,00 & $\begin{array}{r}0 \\
(0,00 \%)\end{array}$ & $\begin{array}{r}\operatorname{Rp} 0,00 \\
(0,00 \%)\end{array}$ & $0,00 \%$ \\
\hline 4. /bajuelmo/ & $\begin{array}{r}35 \\
(8,54 \%)\end{array}$ & $\begin{array}{r}2 \\
(6,67 \%)\end{array}$ & $5,71 \%$ & 2,1 & $\begin{array}{r}0 \\
(0,00 x)\end{array}$ & $0,00 \%$ & 0,00 & $\begin{array}{r}0 \\
(0,00 \%)\end{array}$ & $\begin{array}{r}\operatorname{Rp} 0,00 \\
(0,008)\end{array}$ & $0,00 \%$ \\
\hline 5. /product/ & $\begin{array}{r}32 \\
(7,808)\end{array}$ & $\begin{array}{r}2 \\
(6,67 \%)\end{array}$ & $6,25 \%$ & 5,1 & $\begin{array}{r}0 \\
(0,00 x)\end{array}$ & $0,00 \%$ & 0,00 & $\begin{array}{r}0 \\
(0,008)\end{array}$ & $\begin{array}{r}\operatorname{Rp} 0,00 \\
(0,00 \%)\end{array}$ & $0,00 \%$ \\
\hline 6. /how-to-care-for-tie-dye-t-shirts/ & $\begin{array}{r}27 \\
(6,59 \%)\end{array}$ & $\begin{array}{r}3 \\
(10,000 x)\end{array}$ & $11,11 \%$ & 6,9 & $\begin{array}{r}0 \\
(0,00 x)\end{array}$ & $0,00 \%$ & 0,00 & $\begin{array}{r}0 \\
(0,00 \%)\end{array}$ & $\begin{array}{r}\mathrm{Rp} 0,00 \\
(0,008)\end{array}$ & $0,00 \%$ \\
\hline $\begin{array}{l}\text { 7. /product/baju-tie-dye-about-she/baju-tie-dy } \\
\text { e-pink-kuning/ }\end{array}$ & $\begin{array}{r}23 \\
(5,61 \%)\end{array}$ & $\begin{array}{r}2 \\
(6,67 \%)\end{array}$ & $8,70 \%$ & 5,4 & $\begin{array}{r}\mathbf{0} \\
(0,00 \%)\end{array}$ & $0,00 \%$ & 0,00 & $\begin{array}{r}0 \\
(0,00 \%)\end{array}$ & $\begin{array}{r}\operatorname{Rp} 0,00 \\
(0,00 \%)\end{array}$ & $0,00 \%$ \\
\hline 8. /faq/ & $\begin{array}{r}20 \\
(4,88 \mathrm{~B})\end{array}$ & $\begin{array}{r}1 \\
(3,33 \%)\end{array}$ & $5,00 \%$ & 2,3 & $\begin{array}{r}0 \\
(0,00 x)\end{array}$ & $0,00 \%$ & 0,00 & $\begin{array}{r}0 \\
(0,008)\end{array}$ & $\begin{array}{r}\mathrm{Rp} 0,00 \\
(0,000 \mathrm{~s})\end{array}$ & $0,00 \%$ \\
\hline $\begin{array}{l}\text { 9. /product-about-she/baju-tie-dye-about-sh } \\
\text { e/baju-tie-dye-ungu-about-she/ }\end{array}$ & $\begin{array}{r}19 \\
(4,638)\end{array}$ & $\begin{array}{r}0 \\
(0,00 \%)\end{array}$ & $0,00 \%$ & 8,5 & $\begin{array}{r}\mathbf{0} \\
(0,00 x)\end{array}$ & $0,00 \%$ & 0,00 & $\begin{array}{r}0 \\
(0,00 \%)\end{array}$ & $\begin{array}{r}\operatorname{Rp} 0,00 \\
(0,00 \%)\end{array}$ & $0,00 \%$ \\
\hline 10. /product/baju-elmo/ & $\begin{array}{r}18 \\
(4,39 \%)\end{array}$ & $(10,008)$ & $16,67 \%$ & 16 & $\begin{array}{r}\mathbf{0} \\
(0,00 x)\end{array}$ & $0,00 \%$ & 0,00 & $\begin{array}{r}0 \\
(0,00 \%)\end{array}$ & $\begin{array}{r}\operatorname{Rp} 0,00 \\
(0,00 \%)\end{array}$ & $0,00 \%$ \\
\hline
\end{tabular}

Gambar 12 Ringkasan Halaman Landing Website pada bulan Februari 2021

Pada Gambar 12 merupakan Ringkasan Halaman Landing Website pada bulan Februari 2021. Dapat dilihat bahwa halaman yang sering dilihat atau dikunjungi oleh pengguna yaitu halaman awal dari website yaitu halaman home. Pada halaman home, terdapat 23 tayangan yang ditampilkan pada hasil penelusuran yang dilihat oleh pengguna, 9 jumlah klik di URL situs dari halaman hasil Google penelusuran dan $0 \%$ pada nilai konversi dikarenakan belum terdapat transaksi pembelian pada website About She. Ini bisa dapat dijadikan evaluasi untuk memperbaiki dan mengembangkan halaman home sesuai target pengunjung website agar pengunjung selalu tertarik untuk mengunjungi website.

\section{Hasil Search Engine Optimization (SEO)}

Penerapan SEO untuk website dilakukan dengan menggunakan plugin SEO pada Website. Plugin merupakan paket program yang dapat di install melalui Wordpress [10]. Lalu melakukan optimisasi pada meta description, membuat judul yang menarik, menambahkan gambar, memanfaatkan heading dan sub heading, menyisipkan outbound dan inbound link, meletakkan focus keyphrase seperti pada Gambar 13 dan Gambar 14, sampai score berwarna hijau maka optimasi SEO tersebut sudah bagus [11]. 
Yoast SEO

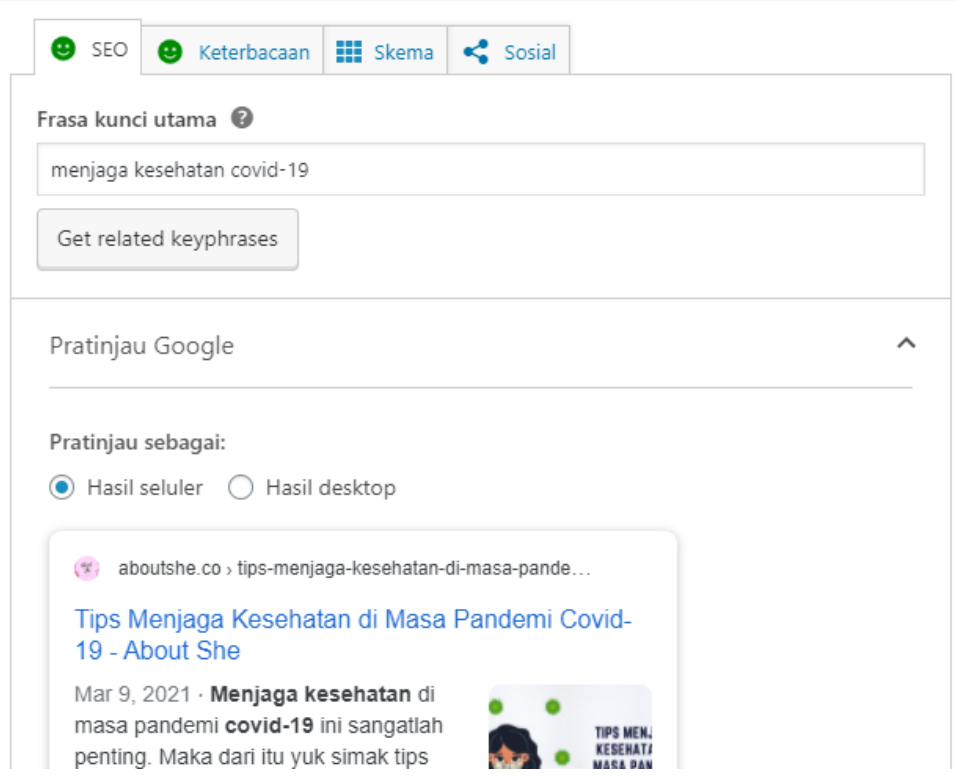

Gambar 13 Optimisasi SEO pada website

\section{Yoast SEO}

(-) Analisis keterbacaan: Bagus

(-) Analisis SEO: Bagus

Gambar 14 Score SEO pada Website

Pada Gambar 15 merupakan hasil dari penerapan Search Engine Optimization (SEO) yang muncul pada halaman pertama pencarian di google. Fungsi dari Search Engine Optimization (SEO) yaitu untuk mendatangkan pengunjung melalui search engine, menaikkan peringkat sebuah website agar selalu terindeks pada search engine sehingga dapat tampil pada halaman utama, membantu dalam menaikkan target penjualan, meminimalkan biaya pemasaran [12]. Dengan memasukkan keyword "baju tiedye aboutshe", pada halaman pencarian google akan menampilkan seperti pada Gambar 9 yang saat di klik akan meredirect ke halaman website About She. Pada penerapan SEO ini memberikan dampak dalam peningkatan jumlah pengguna pada website.

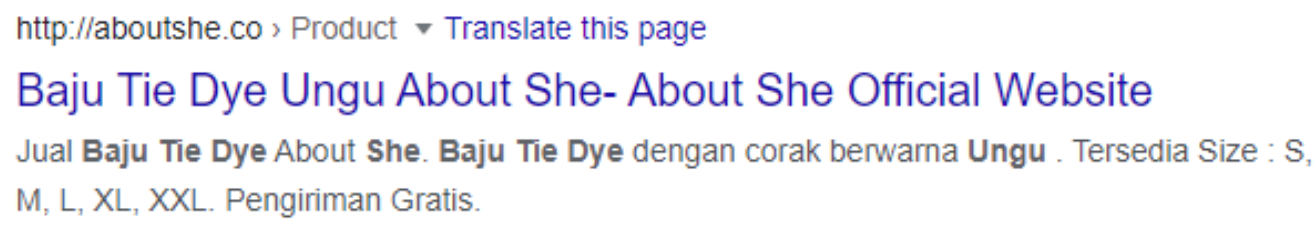




\section{SIMPULAN}

Berdasarkan "penerapan dan analisis digital marketing pada produk fashion", disertai dengan penjelasan sebelumnya, maka diperoleh kesimpulan yaitu media yang paling efektif dari penerapan digital marketing yang telah dilakukan yaitu Instagram dan strategi yang paling tepat untuk meningkatkan engagement yaitu dengan melakukan Giveaway kepada followers Instagram karena memberikan dampak dalam meningkatkan engagement pada Instagram. Maka dari itu lebih efektif jika berfokus pada penerapan digital marketing di social media. Lalu pada website telah diterapkan SEO pada website yang memberikan dampak dalam peningkatan pengunjung baru pada website.

\section{UCAPAN TERIMA KASIH}

Segala puji dan syukur penulis ucapkan kepada Tuhan Yang Maha Esa, penulis dapat menyelesaikan Jurnal Tugas Akhir dengan lancar. Penyusunan Jurnal ini sebagai syarat kelulusan mata kuliah tugas akhir. Untuk itu penulis ucapkan banyak terima kasih atas segala partisipasinya dalam menyelesaikan jurnal ini. Semoga dengan adanya jurnal ini, semua pihak yang membaca dan mendapatkan sesuatu yang berguna. Tuhan Memberkati.

\section{DAFTAR PUSTAKA}

[1] T. Rachmadi, The Power Of Digital Marketing, TIGA Ebook, 2020.

[2] J. Tarigan dan R. Sanjaya, Creative Digital Marketing, Elex Media Komputindo, 2013.

[3] I. Ardiansah and A. Maharani. Optimalisasi Instagram sebagai Media Marketing, CV Cendekia Press, 2021.

[4] J. Helianthusonfri, Belajar Social Media Marketing, Elex media komputindo, 2019.

[5] J. Enterprise, Trik SEO untuk Toko Online, Elex Media Komputindo, 2017.

[6] J. Helianthusonfri, Website Dahsyat Pencetak Uang dengan WordPress, Elex Media Komputindo, 2014.

[7] N. S. Miyata, "Efektivitas Penggunaan Instagram Sebagai Media Promosi Perpustakaan Universitas Kristen Petra," Agora, vol. 7, no. 2 , p. 4, 2019. Instagram, “About Instagram Insights | Instagram Help Center,” Instagram, 2021. [Online]. Available: https://www.facebook.com/help/instagram/788388387972460. [Accessed 13 Juni 2021].

[8] Facebook, “About Page Insights on Facebook," Facebook for Business, 2021. [Online]. Available: https://www.facebook.com/business/help/144825579583746?id=939256796236247. [Accessed 13 Juni 2021].

[9] T. Kelsey, Introduction to Google Analytics, A Guide for Absolute Beginners, Apress, 2017.

[10] B. Nugroho and V., Panduan Pintar SEO Plugins for WordPress, Elex Media Komputindo, 2014.

[11] B. Nugroho, Panduan Pintar Blogger dan Optimasi SEO, Elex Media Komputindo, 2014.

[12] D. Martin, THE BOSS ( Best on SEO \& SEM ): Kitab Besar Panduan Ilmu SEO \& SEM, dari Pemula hingga Mahir, digimind.id, 2020. 